\title{
Frequency of Predisposing Factors and First Choice of Treatment for Headache
}

\author{
Nabeela Safdar', Sadia Farooq², Sania Aziz ${ }^{3}$ \\ ${ }^{1}$ Lahore College of Physical Therapy, LMDC, Lahore. \\ 2 Pakistan Railway Hospital, Rawalpindi \\ ${ }^{3}$ University Institute of Physical Therapy (UOL Isb)
}

Author's Contribution

${ }^{1}$ Conception and design, ${ }^{1-3}$ Collection and assembly of data, Analysis and interpretation of the data, Statistical expertise, Drafting of Article, ${ }^{1}$ Critical revision of the article for important intellectual content, Final approval and guarantor of the article.

\begin{tabular}{l}
\hline Article Info. \\
\hline Received: Feb 19, 2020 \\
Acceptance: Jan 4, 2020 \\
\hline Conflict of Interest: None \\
Funding Sources: None \\
\hline Address of Correspondence \\
\hline Dr Nabeela Safdar \\
nabeelasafdar@gmail.com
\end{tabular}

Cite this article as: Safdar $\mathrm{N}$, Farooq S, Aziz S. Frequency of Predisposing Factors and First Choice of Treatment for Headache. JRCRS. 2021; 9(1). 14-17.

DOI:

https://dx.doi.org/10.53389/JRCRS.20 $\underline{21090103}$

\section{A B S T R A C T}

Background: Headache being one of the most common disorders worldwide is considered among the 10 most disabling conditions for men and women according to World Health Organization(WHO). When it comes to the causative factors that can cause headaches and why some groups of patients are more prone towards developing these headaches,we have identified several risk factors.

Objective: To find out the frequency of predisposing factors and first choice of treatment for headache.

Methodology: Descriptive cross sectional study was conducted from June-November 2014. A sample of 500 participants was conscripted through the purposive non-probability sampling technique. The particulars of predisposing factors and first choice of treatment were documented through a self-structured questionnaire and data was analyzed through SPSS 21.

Results: The study illustrates that most of the participants belonged to the age group 21 to 40 years that is $62.6 \%$. The pain severity was recorded $(46 \%),(43 \%)$, and $(10 \%)$ for mild, moderate, and severe pain correspondingly. Most participants in this study have headache which is intensified by anxiety (42.4\%), inadequate sleep (25\%) and tiredness $(17 \%)$ and most prevalent first choice of treatment used by the participants were NSAIDs (46\%) and proper sleep $(31 \%)$ while rare were herbal remedies and wrap of cloth around head $(2.6 \%)$ and $(2.4 \%)$ correspondingly.

Conclusion: In this cross sectional survey based study we conclude that people with stress and inadequate sleep are most likely to experience a headache in our population, and are using NSAIDS commonly to relief the pain followed by catching up on sleep.

Keywords: Cluster Headache, First line-intervention, Headache Disorders, Risk factors, Tension Type Headache

\section{Introduction}

Almost every person at any stage of life must have experienced a headache, it is the common symptom of many diseases. ${ }^{1}$ The Global Headache Society categorizes headaches into primary and secondary headaches. Primary headaches are not related to underlying disease and consist of migraine, tension-type, and cluster headache whereas Secondary headaches are due to underlying disease condition and comprise of any head pain due to infectious, neoplastic, vascular, and drug related disorders. ${ }^{2}$ One of the commonest complaint found in almost every age group especially young's and adolescents is Headache and is not commonly paid attention to, that is why it results in increased frequency of absentees from schools, colleges and workplaces and ultimately reduced quality of life. ${ }^{3}$ Stress, inadequate sleep, and too much school work (fatigue) are the most commonly reported self-perceived risk factors for headache. ${ }^{4}$ Individuals can feel better by altering their way of life and their regular work, by using some 
relaxation therapy or occasionally they have to take medication for pain relief. ${ }^{5}$

According to study conducted in Karachi the occurrence rate of headache is $86 \%$ from which $43 \%$ had mild, $47 \%$ had moderate and $9 \%$ had severe headache. ${ }^{6}$

Fatima memorial college Lahore conducted a study and determine the occurrence of headache and its indications in medical students and this study showed that most dominant age of headache was 21 years and $57 \%$ students have headache which continues less than one hour and $27 \%$ have a headache which continues from 1 to 4 hour and $7 \%$ have headache which continues for greater than 24 hours. $^{7}$ Majority of headaches were not due to some primary pathology, but the reason was anxiety or muscle tension, fatigue, inadequate sleep and many other. ${ }^{8}$

Student's population is far more affected by headache than does the normal people and it results in increase absentees from schools, colleges or students being unable to study due to headache, thus minimizing their overall academic performance. 7,9 Preliminary measures should be taken in order to avoid developing risk factors that cause headache in these students and there is an utmost need for further studies and researches that address main causes of headache and its curative measures.

This study will help to identify the most common types of headaches, their predisposing factors and first choice of treatment used by people in order to treat them.

\section{Methodology}

A descriptive cross sectional community based study was conducted from January- June 2015. A sample of 500 participants was recruited through non probability purposive sampling technique from Lahore and Islamabad. The sample size was calculated by using WHO calculator. Informed consent was taken from all the participants earlier to study. The particulars were documented through a self-structured questionnaire and pain was measured using visual analogue scale (VAS).

Inclusion criteria: Adolescents (13 to 18 years) and Adults (19 to 44 years) having primary and secondary headache were included in study.
Exclusion criteria: Participants having headache associated with chronic medical illness like brain tumors, post-traumatic headache and headache due to hormonal fluctuation were excluded from study. Self-structured validated Questionnaire was used which include series of questions about duration, region, predisposing factors of headache \& most common first choice of treatment used for headache was self-filled by participants. The descriptive analysis of data was done through SPSS 21 \{Statistical Package for Social Sciences\} software.

\section{Results}

The results are given in graphical representation below (Fig. 1, 2). The majority of the participants belonged to age group 21 to 40 years that is $62.6 \%$ and the pain severity was recorded $46 \%, 43 \%$ and $10 \%$ for mild, moderate and severe pain correspondingly. The significant descriptions of statistical analysis are given here for valuation. 500 participants were recruited; Of the 500 participants, females are more in number $(64 \%$, $\mathrm{N}=322$ ) compared to males ( $36 \%, \mathrm{~N}=178)$. $42 \%$ of headaches are aggravated by stress, $25 \%$ by inadequate sleep, $17 \%$ by fatigue, $8 \%$ by viral flu, and $6 \%$ by others (dehydration, skipping meals, loud noises, smoking). 46\% of headaches are cured by NSAIDs, $31 \%$ by proper sleep, $7 \%$ by caffeine intake, $5 \%$ by relaxation therapy, and $2 \%$ by herbal remedies, and wrap of cloth around head.

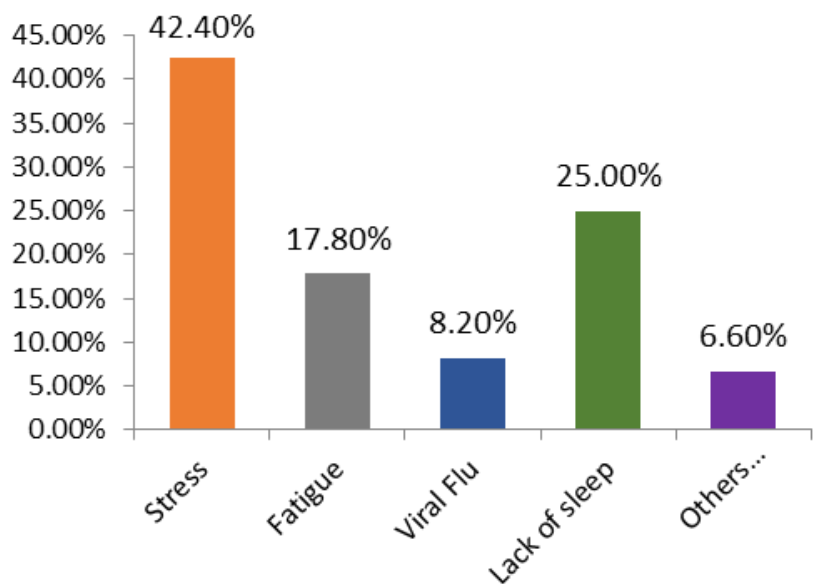

Figure 1. Shows the frequency of Aggravating factors of Headache 


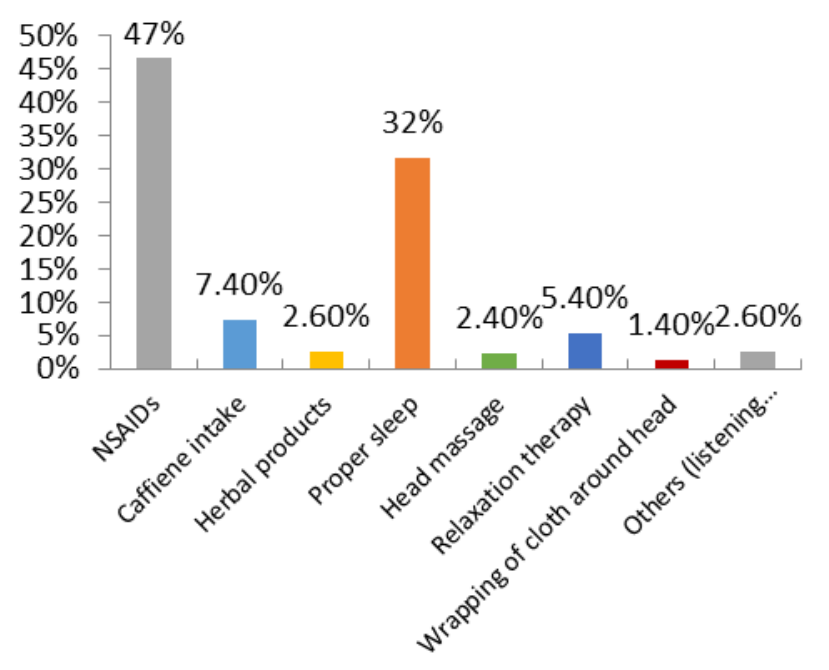

Figure II. Shows the frequency of First line of intervention

\section{Discussion}

The results of this study shows that stress, lack of sleep and fatigue are the most common aggravating factors for headache and NSAIDs, regular/proper sleep, and caffeine intake is used as first line of intervention for headache. Several studies are supporting our point of view of females being more effected by headaches and stress being the most common aggravating factor for migraine, tension type headaches as also shown by work of David et al \& Egilius. ${ }^{10,11}$

Due to lack of literature and studies regarding risk factors for headache and first line of interventions used, there should further exploration of predisposing factors and identification of first choice of treatment to formulate better preventive and curative measures and to reduce the frequency of people affected by headaches, thus overall improving health status and quality of life.

Contrary to some studies that support the use of herbal medicine for headache, we found herbal medicine as a cure for headache as a least used method, it may be due to improved quality and access of healthcare, people are more oriented towards taking Allopathic medicine for early relief of symptoms. ${ }^{12,13}$

This study has highlighted the importance of headache and strategies to remediate it, as it is found to be the most common symptom of many illnesses affecting large number of population.
In our society family responsibilities, lack of proper diet, and increased workload leads towards fatigue, lack of sleep which were found to be strongly associated with headaches. ${ }^{14}$

People should be encouraged to try natural remedies instead of taking NSAIDs that have many side effects besides their therapeutic uses. Proper sleep, on time meals, and avoidance of stress causing factors also prove to be effective in relieving headaches so that headache could no more be an excuse from carrying out work or having fun and joy. ${ }^{15}$

\section{Conclusion}

In this cross sectional survey based study we conclude that people with stress and inadequate sleep are most likely to experience headache in our population, and are using NSAIDS commonly to relief the pain followed by catching up on sleep.

\section{References}

1. Benjamin Wedro M, FACEP, FAAEM. Headache Related Diseases \& Conditions. [updated May; cited 2013]; 28 ]. Available from:

http://www.medicinenet.com/headache/article.htm.

2. Steiner TJ, Birbeck GL, Jensen R, Katsarava Z, Martelletti $P$, Stovner LJ. The global campaign, world health organization and lifting the burden: collaboration in action. Springer; 2011.

3. Kacperski J, Kabbouche MA, O'Brien HL, Weberding JL. The optimal management of headaches in children and adolescents. Ther Adv Neurol Disord.. 2016;9(1):53-68.

4. Astrid Milde-Busch, Andreas Straube, Florian Heinen, Kries Rv. Identified risk factors and adolescents' beliefs about triggers for headaches: results from a crosssectional study. J Orofac Pain. 2012;13(8):639-43.

5. Lance JW, Goadsby PJ. Mechanism and management of headache: Elsevier, Butterworth, Heinemann Philadelphia; 2005.

6. Kafeel H, Rukh R. Prevalence of headache in general population of Karachi, Pakistan. J App pharm. 2014;6(3):308-13.

7. ERUM S. Headache Prevalence, Patterns and Symptoms Amongst Medical Students at Fatima Memorial College, Lahore.

8. Buman MP, King AC. Exercise as a treatment to enhance sleep. American J. Lifestyle Med. 2010;4(6):500-14.

9. Siddiqui SJ, Shamim SMS, Hashmi AM. Prevalence and patterns of headache in school children in Karachi. Prevalence. 2006;56(5):215

10. David D. Celentano MSLaWFS. Gender differences in the experience of headache. social science and medicine.30(12): 1289-95. 
11. Egilius L.H. Spierings MD P, Anniek H. Ranke BSc, Peter C. Honkoop MSc. Precipitating and aggravating factors of migraine versus tension type headache. The Journal of Head and Face Pain. 2001;41(6): 554-8.

12. MD ML. Herbal treatment of Headache. The Journal of Head and Face Pain. 2012;52.

13. Verhagen AP, Damen L, Berger MY, Lenssinck ML, Passchier J, Kroes BW. [Treatment of tension type headache: paracetamol and NSAIDs work: a systematic review]. Ned Tijdschr Geneeskd. 2010;154:A1924. Epub
2010/08/12. Behandeling van spanningshoofdpijn: paracetamol en NSAID's werken: een systematische review.

14. Al-Shimmery EK. Precipitating and relieving factors of migraine headache in 200 iraqi kurdish patients. Oman medical journal. 2010;25(3):212.

15. David W. Dodick MD EJEM, James M. Parish MD. Clinical, Anatomical, and Physiologic Relationship Between Sleep and Headache. The Journal of Head and Face Pain. 2003;43. 